RESEARCH NOTE

\section{Protein Deficiency Impairs the Schistosomicidal Action of Praziquantel}

\section{SF Lima ${ }^{+}$, CTM Souza*, LQ Vieira, PMZ Coelho*/**}

\begin{abstract}
Departamento de Bioquímica e Imunologia
*Departamento de Parasitologia, Instituto de Ciências Biológicas, Universidade Federal de Minas Gerais, Av. Antônio Carlos 6627, 31270-91 Belo Horizonte, MG, Brasil **Santa Casa de Misericórdia de Belo Horizonte, Belo Horizonte, MG, Brasil
\end{abstract}

\section{Key words: nutrition - schistosomicidal drug - Schistosoma mansoni}

The synergism between schistosomicidal drugs and the host immune system has been currently described in the literature. Antimonium and potassium tartarate, oxamniquine and praziquantel [PZQ are not as effective in immunocompromised hosts as it is in normal ones (MJ Doenhoff et al. 1991 Parasitol Today 7: 16-18)]. Accordingly to World Health Organization, PZQ is the drug of choice to treat schistosomiasis (WHO 1982 Report of the scientific meeting on schistosomiasis, TDR-SCH-SWG (3)/82.3).

Geographical distribution of schistosomiasis mansoni is very coincident with areas where poverty is widespread. In such areas undernutrition is rife more than an exception. It has been shown that protein deficiency impairs immune responses, especially cell mediated ones. Severe undernutrition imposes a drop on the proliferative response of human stimulated lymphocytes (R Ortiz et al. 1995 Mutat Res 334: 235-241), numbers of T CD4 ${ }^{+}$ and $\mathrm{T} \mathrm{CD} 8^{+}$cells are significantly reduced (MI Joffe et al. 1983 J Clin Lab Immunol 10: 97-101). Resident macrophages of protein deficient mice produce higher amounts of oxygen reactive species in response to phorbol miristate acetate or

This work was supported by CNPq, Fapemig and Pronex. ${ }^{+}$Corresponding author. Fax: +55-31-499.2970.

Received 4 May 1998

Accepted 31 August 1998 opsonized zymozan suggesting that these cells would be able to cause more tissue damage than cells derived from well nourished animals (S Teshima 1995 J Nutr Sci Vitaminol 41: 127-137).

The purpose of this study was to access the effectiveness of PZQ in a host whose immune system has been altered by protein deficiency. C57B1/ 6 females were fed diets containing 5 or $20 \%$ protein for three weeks and then protein status were determined. Diets were prepared in accordance with AOAC (Association of Official Analytical Methods 1980. In Official Methods of Analysis of the AOAC, 13th ed., AOAC, Washington, DC, 127 pp) and were adequate in all nutrients, except in the amount of protein added to the deficient diet. In brief, control diet contained 66\% corn starch (Maizena, Refinações de Milho Brasil, Brazil), $20 \%$ casein, $5 \%$ mineral mixture (done in accordance with AOAC loc. cit.), $7 \%$ soya oil, $1 \%$ vitamin mixture (AOAC loc. cit.) and $1 \%$ cellulose. Deficient diet was made by $74 \%$ corn starch, $5 \%$ casein, $5 \%$ mineral mixture (AOAC loc. cit.), $5 \%$ soya oil, $1 \%$ vitamin mixture (AOAC loc. cit.) and $10 \%$ cellulose. Diets were kept frozen, in the dark, and $\mathrm{E}$ vitamin $(0.001 \%)$ and hydroxytoluene butylate $(0.0005 \%)$ were added to prevent oxidation. After this period mice were inoculated subcutaneously with 30 cercariae (LE strain) and, eight weeks later, at the acute phase of infection, half of each group was treated with $400 \mathrm{mg} / \mathrm{kg}$ of PZQ (Cestox, Merck, Germany). Twenty days post drug treatment all animals, treated and non-treated, were killed by cervical dislocation, perfused with saline 0.85\% containing heparin (Liquemine, $200 \mathrm{ui} / \mathrm{l}$ ) and recovered parasites were immediately counted.

Protein deficiency was shown by two parameters: group weight and the reduction of serum albumin levels. Mice were weighted twice a week and, at infection time, three weeks after diets starting, control animals were significantly heavier than deficient ones (16.24 $\mathrm{g} \pm 1.49$ for control group and $11.06 \pm 1.43$ for deficient group, $\mathrm{p}<$ 0.0000001 ). As expected sera albumin levels, determined by means of bromocresol green assay (Analysa), were also significantly different at infection time, $3.085 \mathrm{~g} / \mathrm{dl} \pm 1.030$ for control group and $1.668 \mathrm{~g} / \mathrm{dl} \pm 0.902$ for deficient group $(\mathrm{p}<$ 0.000002 ). Despite the reduction of serum albumin concentration, total serum protein content, measured by means of biuret assay (Analysa), was not significantly diminished by the deficient diet, $5.21 \mathrm{~g} / \mathrm{dl} \pm 0.32$ for control fed animals and $5.08 \pm$ 0.61 for protein deficient fed ones. It is possible that contaminations of our samples with hemoglobin would have contributed to this picture.

The number of worms recovered from non treated groups was similar. From 30 cercariae in- 
jected the mean recovery was $12.80 \pm 5.49$ for control group and $10.75 \pm 2.06$ for protein deficient animals (Table). It seems that parasite evolution was not affected by protein status of the host. Upon PZQ treatment the effects were then noticed: all the worms were eliminated by control diet fed animals, on the other hand, $85 \%$ of deficient animals remained infected (Table). There are some possible explanations for this. It is possible that the drug acting in synergy with an altered, maybe less responsive, protein deprived host immune system was not efficient enough to eliminate all the parasites. PZQ action upon $S$. mansoni membrane, leading to membrane destabilization and subsequent exposure of antigenic epitopes (SF Lima et al. 1994 Parasitology 109: 469-477) would had happened as expected, but the host immune response against these newly exposed antigenic molecules would be impaired and could not induce worms elimination. A second explanation would be that those protein deficiency caused worm tegumental quantitative and qualitative alterations interfering with PZQ-membrane interaction and resulting in smaller surface damage. The degree and the nature of damage that must be inflicted before individual parasites are severely and definitively damaged are unknown. Some works have been implying that tegumental damage and the consequent exposure of antigenic molecules are events absolutely necessary to commit host immune cells against $S$. mansoni surface (W Harnett \& JR Kusel 1986 Parasitology 93: 401-405). Finally, a third event that could explain the impaired ability of protein deficient animals to eliminate adult worms would be the reduced concentration of circulating albumin. K Steiner et al. (1976 Eur J Drug Metab Pharmacokin 1: 85-95) showed that $80 \%$ of PZQ in serum is bound to proteins, especially albumin. As a consequence of the reduced levels of circulating albumina in the deficient group it would be possible that smaller amounts of the drug would reach the worm.

A lot has to be done to solve these questions. But the final conclusion of this work has important implications in the field of chemotherapy. Protein deficient is not as efficient as well nourished mice in eliminating $S$. mansoni worms upon PZQ treatment. Would humans be?

TABLE

Worms recovered from control or protein deficient fed mice treated or not with praziquantel

\begin{tabular}{|c|c|c|c|c|}
\hline \multirow{3}{*}{ Mice number } & \multicolumn{4}{|c|}{ Number of recovered worms ${ }^{a}$} \\
\hline & \multicolumn{2}{|c|}{ Control diet } & \multicolumn{2}{|c|}{ Protein deficient diet } \\
\hline & Non-treated & Treated & Non treated & Treated \\
\hline 1 & 21 & 0 & 13 & 1 \\
\hline 2 & 7 & 0 & 11 & 1 \\
\hline 3 & 8 & 0 & 8 & 2 \\
\hline 4 & 17 & 0 & 11 & 0 \\
\hline 5 & 10 & 0 & 14 & 1 \\
\hline 6 & 14 & 0 & 7 & 1 \\
\hline 7 & 12 & 0 & 12 & $*$ \\
\hline 8 & 18 & 0 & $*$ & $*$ \\
\hline 9 & 9 & 0 & $*$ & $*$ \\
\hline 10 & 11 & $*$ & $*$ & $*$ \\
\hline $\mathrm{m}+\mathrm{s} \cdot \mathrm{d}^{b}$ & $12.70+4.43$ & $0.00+0.00^{c}$ & $10.85+2.36$ & $1.00+0.63^{c}$ \\
\hline
\end{tabular}

$a$ : animals infected with 30 cercariae via s.c.; $b$ : calculated with T test using the program Sigmaplot (Jandel Scientific Corporation); $c$ : indicates a statistically significant difference, $\mathrm{p}<0.000003 ; *$ animals died before perfusion. 